\title{
Comparison of stage III mucinous and serous ovarian cancer: a case-control study
}

\author{
Zeliha Firat Cuylan', Emine Karabuk ${ }^{2}$, Murat OZ ${ }^{1^{*}}$ (D), Ahmet Taner Turan ${ }^{3}$, Mehmet M. Meydanli ${ }^{1}$, Salih Taskin ${ }^{4}$, \\ Mustafa Erkan Sari ${ }^{1}$, Hanifi Sahin ${ }^{1}$, Suat C. Ulukent ${ }^{5}$, Ozgur Akbayir ${ }^{6}$, Kemal Gungorduk ${ }^{7}$, Tayfun Gungor ${ }^{1}$, \\ Mehmet F. Kose ${ }^{2}$ and Ali Ayhan ${ }^{8}$
}

\begin{abstract}
Background: The purpose of this case-control study was to compare the prognoses of women with stage III mucinous ovarian carcinoma (MOC) who received maximal or optimal cytoreduction followed by paclitaxel plus carboplatin chemotherapy to those of women with stage III serous epithelial ovarian cancer (EOC) treated in the similar manner.
\end{abstract}

Methods: We performed a multicenter, retrospective review to identify patients with stage III MOC at seven gynecologic oncology departments in Turkey. Eighty-one women with MOC were included. Each case was matched to two women with stage III serous EOC in terms of age, tumor grade, substage of disease, and extent of residual disease. Survival estimates were measured using Kaplan-Meier plots. Variables predictive of outcome were analyzed using Cox regression models.

Results: With a median follow-up of 54 months, the median progression-free survival (PFS) for women with stage III MOC was 18.0 months (95\% Cl; 13.8-22.1, SE: 2.13) compared to 29.0 months (95\% Cl; 24.04-33.95, SE: 2.52) in the serous group $(p=0.19)$. The 5 -year overall survival rate of the MOC group was significantly lower than that of the serous EOC group ( $44.9 \%$ vs. $66.3 \%$, respectively; $p<0.001$ ). For the entire cohort, presence of multiple peritoneal implants (Hazard ratio [HR] 2.39; 95\% confidence interval [Cl], 1.38-4.14, $p=0.002$ ) and mucinous histology (HR 2.28; 95\% Cl, 1.53-3.40, $p<0.001$ ) were identified as independent predictors of decreased OS.

Conclusion: Patients with MOC seem to be 2.3 times more likely to die of their tumors when compared to women with serous EOC.

Keywords: Analyses, survival, Epithelial ovarian cancer, Mucinous adenocarcinoma, Serous cystadenocarcinoma

\section{Introduction}

Primary mucinous ovarian carcinoma (MOC) represents a biochemically and genetically distinct subgroup of epithelial ovarian cancer (EOC) [1]. MOC accounts for $3 \%$ [2] to $10 \%$ [3] of all ovarian carcinomas. Most patients with MOC are diagnosed at an early stage and therefore it confers a favorable prognosis [3]. However, once the disease is advanced, mucinous histology has a poorer outcome compared to the other histologic subgroups [4-7].

\footnotetext{
* Correspondence: ozmurat@gmail.com

'Department of Gynecologic Oncology, Zekai Tahir Burak Women's Health Training and Research Hospital, Faculty of Medicine, University of Health Sciences, Ankara, Turkey

Full list of author information is available at the end of the article
}

Mucinous histology has consistently been reported as an independent adverse prognostic factor in advanced EOC $[6,8,9]$ and the outcomes of MOCs are significantly different from EOCs with serous histology [10]. The reason for poor prognosis of advanced MOC has been suggested to be either the aggressive biology of mucinous tumor or chemoresistance or both $[9,11,12]$.

Approximately $14 \%$ of all MOCs are diagnosed as stage III disease [7]. Response rates to standard platinum-based chemotherapy are low (12.5-38.5\%) among women with MOC, and debulking to minimal or no residual disease (RD) remains the standard of care [13]. It has been reported that overall survival (OS) is 3.8 fold increased in patients who have received optimal cytoreductive surgery

(c) The Author(s). 2018 Open Access This article is distributed under the terms of the Creative Commons Attribution 4.0 International License (http://creativecommons.org/licenses/by/4.0/), which permits unrestricted use, distribution, and 
(CRS) compared to the patients who have had suboptimal cytoreduction [14].

We wondered whether the worse prognosis associated with mucinous histology is also valid when age, tumor grade, substage of disease, and extent of RD are matched with serous histology in women with stage III EOC who have undergone primary CRS followed by standard intravenous paclitaxel plus carboplatin chemotherapy. Given the low frequency of stage III MOC, a multicenter effort was essential in order to achieve an adequate number in this case-control study. The objective of this retrospective, multicenter study was to compare prognostic factors of women with stage III MOC to those of women with stage III serous EOC treated in the same fashion.

\section{Methods}

After Institutional Review Board approval (IRB Approval Number: 05, Date: November 7th 2017), institutional databases for EOC were utilized to identify eligible cases. The databases consisted of individual patients with EOC who underwent upfront surgery between January 1998 and December 2016 at seven gynecologic oncology departments in Turkey. All patients provided an informed consent at admission for storage of their clinical information and for research use of their clinical data.

The case group consisted of EOC patients with histopathologically confirmed Stage III [15] MOC. We included only the patients with optimal or maximal CRS in the upfront surgery. We excluded the patients who had RD greater than $1 \mathrm{~cm}$. Since the case group included only women having pure mucinous histology; women with mixed histologies including mucinous tumors combined with endometrioid, serous, clear-cell, and/or other histologic types were excluded. The patients who received neoadjuvant chemotherapy, women with synchronous malignancies, and those with incomplete medical records were also excluded from the study.

Using a dependent random sampling method, each case was matched to two patients with serous EOC from a series of 783 women who had undergone maximal or optimal CRS ( $R D \leq 1 \mathrm{~cm}$ ) followed by paclitaxel and carboplatin combination chemotherapy for the same period. In the case and control groups, pairs were matched in terms of age at diagnosis ( $+/-10$ years), year of diagnosis, grade of the tumor (grade 1,2 , or 3 ), substage (stage IIIA $A_{1}$, IIIA $_{2}$, IIIB, and IIIC), and extent of RD (maximal vs. optimal debulking). While selecting the patients in the control group, we were blinded to the outcomes of the patients in order to prevent possible patient selection bias.

The following clinical data were extracted from patients' medical, surgical, pathology, and chemotherapy reports: demographic characteristics, preoperative serum cancer antigen 125 (CA 125) levels, type and date of surgical procedure, presence of multiple $(\geq 2)$ peritoneal implants, ascites status, results of peritoneal washings (negative or positive), appendiceal involvement, omental involvement, size of RD after surgery, stage of disease, time to recurrence, length of follow-up and survival. Pathologic characteristics of the disease were abstracted from original pathology reports. Data were collected from departments with an online standardized form.

Gynecologic oncologists performed all of the operations with the aim of achieving complete cytoreduction. After primary CRS, RD was recorded according to the assessment by the surgical team. Retroperitoneal lymph node dissection was performed after completion of intraabdominal cytoreduction. Number of total lymph nodes (LNs) removed, number of para-aortic LNs removed, and number of pelvic LNs removed and number of metastatic LNs were noted.

All pathologic specimens of the upfront surgery were evaluated and interpreted by expert gynecologic pathologists of the participating institutions with experience in gynecological malignancies but were not reviewed centrally in the current study.MOC was diagnosed after examination of permanent sections. Immunuhistochemical study was performed in women where metastatic tumors could not be excluded. With careful exclusion of noninvasive and metastatic mucinous tumors, women who had final pathologic diagnoses as "primary MOCs" were included in the case group.

The World Health Organization (WHO) criteria were used for histologic classification of the tumors $[16,17]$. Architectural grading was defined by standard International Federation of Gynecology and Obstetrics (FIGO) criteria. All tumors were staged according to the FIGO staging system, which was revised in 2014 [15]. In patients treated before 2014, stage was adapted to the FIGO 2014 staging system retrospectively using surgical and pathologic assessment.

All patients (cases and controls) received adjuvant chemotherapy. The standard first line chemotherapy protocol included paclitaxel $175 \mathrm{mg} / \mathrm{m}^{2}$ plus carboplatin at the dose of area under curve (AUC) 5 or 6 every 21 days for 6 cycles. Targeted agents (i.e. bevacizumab) were not included in the first line chemotherapy. Platinum refractory disease was defined as disease progression on first-line platinum based regimen, whereas platinum resistant disease included patients with tumor progression within 6 months of completion of platinum based chemotherapy.

We followed-up the patients quarterly for the first 2 years, biannually until 5 years, and annually thereafter. The follow-up visits included physical and gynecologic examinations, and serum CA 125 measurements. Each patient was assessed for relapse with imaging studies and serum CA 125 measurements. Treatment of the recurrences (surgery and/or chemotherapy) was applied according to the institutional practices at that time. 
Survival data were last calculated on 31st December 2016. The survival status of the patients was determined as alive or dead at the time of the last follow-up visit. Survival status for all the subjects was confirmed by social security death index search.

Maximal cytoreduction was defined as no visible RD left in-situ (microscopic RD) after primary CRS. Optimal cytoreduction was defined as a RD less than or equal to $1 \mathrm{~cm}$ maximal diameter of the largest tumor deposit at the end of the primary surgery. Similarly, suboptimal cytoreduction was defined as $>1 \mathrm{~cm}$ of RD. Lymphadenectomy was defined as the dissection of pelvic and para-aortic LN's at the same time. Progression-free survival (PFS) was defined as the time, in months, from the primary surgery to the documented recurrence with clinical examination and/or radiologic imaging; or death from any cause, whichever occurred first, or the date of last follow-up for patients remaining alive without recurrence. Patients who had no active disease at the last contact were censored in the PFS analysis. Overall survival (OS) was defined as the time, in months, between the date of primary surgery to the date of death or the last follow-up. Surviving patients were censored at their last known follow-up.

Survival curves were generated using Kaplan-Meier plots and survivals were compared using the log-rank test. The chi-squared test was used for nominal variables. For continuous variables, Student's $t$-test and the Mann-Whitney $U$ tests were used for continuous variables with and without normal distribution, respectively. Cox logistic regression models were used to determine co-variates affecting survival, and presented as hazard ratios (HRs) with 95\% confidence interval (CI), unadjusted or adjusted for all factors. All variables with a $p$ value $<0.05$ in the univariate analysis were included in the multivariate analysis. All statistical analyses were performed with the SPSS software version 23.0 (IBM Corp., Armonk, NY, USA). A $p$ value $<0.05$ was considered statistically significant.

\section{Results}

One hundred and sixty-four women were identified with a postoperative pathology-proven diagnosis of stage III primary $\mathrm{MOC}$ at seven participating centers during the study period. We excluded 74 women who had suboptimal CRS, six women who received neoadjuvant chemotherapy, one with synchronous breast cancer and two women with incomplete medical records. Therefore, 81 women with stage III MOC were included in the final analysis. These 81cases were compared to 162 controls with serous EOC who had maximal or optimal CRS followed by paclitaxel plus carboplatin combination chemotherapy.
Table 1 demonstrates the demographic and clinicopathologic characteristics of the study population. Age, menopausal status, presence of multiple peritoneal implants, tumor grade, substage of disease, positive peritoneal cytology, extent of RD, appendiceal involvement, and omental involvement were similar between the cases and controls. Patients with serous EOC were more likely to have elevated median baseline serum CA 125 levels (514 IU $/ \mathrm{ml}$ vs. $126 \mathrm{IU} / \mathrm{ml} ; p=0.022)$, ascites $(125 / 162$ vs. $42 / 81 ; p<0.001)$, and positive retroperitoneal LNs $(116 / 162$ vs. $21 / 81 ; p<0.001)$. The median number of total LNs harvested, the median number of pelvic LNs removed were significantly higher in the serous EOC patients when compared to women with MOC as well as the median number of para-aortic LNs removed (49 vs. $34 ; p<0.001,32$ vs. $24 ; p=0.003$, and 15 vs. $11 ; p<$ 0.001 , respectively). In both of the groups, stage IIIA $_{1}$, IIIA $_{2}$, IIIB and IIIC disease were noted in $16.1 \%, 7.4 \%$, $16.0 \%$ and $60.5 \%$, respectively.

With a median follow-up of 54 months (range, 5216 months), the median PFS for women with stage III MOC was 18.0 months (95\% CI; 13.8-22.1, SE: 2.13) compared to 29.0 months (95\% CI; 24.04-33.95, SE: $2.52)$ in the serous EOC group $(p=0.19)$ (Fig. 1). The 5 -year OS rate of the MOC group was significantly lower than that of the serous EOC group ( $44.9 \%$ vs. $66.3 \%$, respectively; $p<0.001$ ) (Fig. 2).

Platinum refractory disease was detected more frequently in the mucinous group $(n=18,22.2 \%)$ than in the serous group $(n=9,5.5 \%) \quad(p<0.001)$. However, the number of women with platinum resistant disease was comparable between the mucinous and serous groups $(n=12$ [14.8\%] and $n=21$ [12.9\%], respectively, $p=0.69$ ).

For the entire cohort, univariate analysis revealed substage of disease (stage IIIA 1 vs. other stages) $(p<0.001)$, positive peritoneal cytology $(p=0.01)$, appendiceal involvement $(p<0.001)$, omental involvement $(p<0.001)$, and presence of multiple peritoneal implants $(p<0.001)$ as significant factors for decreased PFS. In multivariate analysis, presence of multiple peritoneal implants (HR 2.1, 95\% CI 1.40-3.14; $p<0.001$ ) remained as the sole independent risk factor for decreased PFS.

For the entire cohort, univariate analysis revealed substage of disease (stage IIIA $_{1}$ vs. other stages) $(p=0.001)$, appendiceal involvement $(p<0.001)$, omental involvement $(p<0.001)$, presence of multiple peritoneal implants $(p<$ $0.001)$, and mucinous histology $(p<0.001)$ as significant factors for decreased OS (Table 2). Multivariate analysis demonstrated presence of multiple peritoneal implants (HR 2.39; 95\% CI, 1.38-4.14, $p=0.002$ ) and mucinous histology (HR 2.28; 95\% CI, 1.53-3.40, $p<0.001$ ) as independent predictors of decreased OS (Table 2).

Finally, 81 patients with stage III MOC were separately analyzed. Univariate analysis revealed substage of disease 
Table 1 Demographic and clinicopathologic characteristics of the study population $(n=243)$

\begin{tabular}{|c|c|c|c|}
\hline \multirow[t]{2}{*}{ Characteristics } & \multirow{2}{*}{$\begin{array}{l}\text { MOC } \\
\text { Values, n (\%) }\end{array}$} & \multicolumn{2}{|l|}{ Serous EOC } \\
\hline & & Values, n (\%) & $p$ \\
\hline Age, y (median, range) & $53.9(18-77)$ & $53.4(28-81)$ & 0.73 \\
\hline \multicolumn{4}{|l|}{ Menopausal status } \\
\hline Postmenopausal & $49(60.5 \%)$ & $98(60.5 \%)$ & 1.0 \\
\hline Premenopausal & $32(39.5 \%)$ & $64(39.5 \%)$ & 1.0 \\
\hline CA 125 (IU/ml) (median, range) & $126(4-4891)$ & $514(8-27,580)$ & 0.022 \\
\hline \multicolumn{4}{|l|}{ Grade } \\
\hline 1 & $29(35.8 \%)$ & $58(35.8 \%)$ & 1.0 \\
\hline $2-3$ & $52(64.2 \%)$ & $104(64.2 \%)$ & 1.0 \\
\hline \multicolumn{4}{|l|}{ Stage } \\
\hline$\| I A 1$ & $13(16.1 \%)$ & $26(16.1 \%)$ & 1.0 \\
\hline IIIA2 & $6(7.4 \%)$ & $12(7.4 \%)$ & 1.0 \\
\hline$\| \mathrm{II}$ & $13(16 \%)$ & $26(16 \%)$ & 1.0 \\
\hline IIIC & $49(60.5 \%)$ & $98(60.5 \%)$ & 1.0 \\
\hline \multicolumn{4}{|l|}{ Debulking } \\
\hline Optimal & $54(66.7 \%)$ & $108(66.7 \%)$ & 1.0 \\
\hline Maximal & $27(33.3 \%)$ & $54(33.3 \%)$ & 1.0 \\
\hline \multicolumn{4}{|l|}{ Ascites } \\
\hline Present & $42(51.9 \%)$ & $125(77.2 \%)$ & $<0.001$ \\
\hline Absent & $39(48.1 \%)$ & $37(22.8 \%)$ & \\
\hline \multicolumn{4}{|l|}{ Peritoneal Cytology } \\
\hline Positive & $61(75.3 \%)$ & $137(84.6 \%)$ & 0.114 \\
\hline Negative & $20(24.7 \%)$ & $25(15.4 \%)$ & \\
\hline $\begin{array}{l}\text { Number of LNs removed } \\
\text { (median, range) }\end{array}$ & $34(19-96)$ & $49(21-203)$ & $<0.001$ \\
\hline Pelvic LNs & $24(10-75)$ & $32(10-101)$ & 0.003 \\
\hline Para-aortic LNs & $11(5-54)$ & $15(5-102)$ & $<0.001$ \\
\hline \multicolumn{4}{|l|}{ Retroperitoneal LN metastases } \\
\hline Present & $21(25.9 \%)$ & $91(56.2 \%)$ & $<0.001$ \\
\hline Absent & $60(74.1 \%)$ & $71(43.8 \%)$ & \\
\hline \multicolumn{4}{|l|}{ Appendiceal Involvement } \\
\hline Present & $29(35.8 \%)$ & $59(36.4 \%)$ & 1.0 \\
\hline Absent & $52(64.2 \%)$ & $103(63.6 \%)$ & \\
\hline \multicolumn{4}{|l|}{ Omental Involvement } \\
\hline Present & $61(75.3 \%)$ & $113(69.8 \%)$ & 0.451 \\
\hline Absent & $20(24.7 \%)$ & $49(30.2 \%)$ & \\
\hline \multicolumn{4}{|l|}{ Peritoneal Involvement } \\
\hline Present & $57(70.4 \%)$ & $103(63.6 \%)$ & 0.318 \\
\hline Absent & $24(29.6 \%)$ & $59(36.4 \%)$ & \\
\hline \multicolumn{4}{|l|}{ Status } \\
\hline Alive & $32(39.5 \%)$ & 112 (69.1\%) & \\
\hline Dead & $49(60.5 \%)$ & $50(30.9 \%)$ & \\
\hline Follow-up, months (median, range) & $21(1-216)$ & $46(1-121)$ & \\
\hline
\end{tabular}

Abbreviations: $n$ Number, LN Lymph node, y year, MOC Mucinous Ovarian Carcinoma, EOC Epithelial Ovarian Carcinoma, SD Standard Deviation (stage IIIA $_{1}$ vs. other stages) $(p<0.001)$, omental involvement $(p=0.004)$, and optimal debulking $(p<0.001)$ as significant factors for decreased PFS. In the multivariate Cox regression model, only maximal CRS (HR 0.48; 95\% CI, $0.23-0.97, p=0.041$ ) was identified as an independent predictor of increased PFS. For women with stage III MOC, univariate analysis revealed substage of disease (stage IIIA ${ }_{1}$ vs. other stages) $(p=0.002)$, omental involvement $(p=$ $0.008)$, and optimal debulking $(p<0.001)$ as significant factors for decreased OS (Table 3). In multivariate analysis, only maximal CRS (HR 0.37; 95\% CI, 0.16-0.86, $p=0.021$ ) remained as an independent predictor of increased OS (Table 3). At the time of reporting, of 81 women with stage III MOC, 49 (60.5\%) were dead whereas 32 (39.5\%) were alive. The corresponding figures were found to be $50(30.9 \%)$ and $112(69.1 \%)$, respectively in the serous EOC group.

\section{Discussion}

Our results indicate that presence of multiple peritoneal implants and mucinous histology seem to be the independent predictors of decreased OS in a cohort of 243 women who have undergone maximal or optimal CRS and found to have either mucinous or serous stage III EOC at the end of final pathology report. Patients with MOC were 2.3 times more likely to die of their tumors when compared to women with serous EOC.

The retrospective nature of the study and lack of central pathology review seem to be the major limitations of the current study. Patients were treated and observed at seven different gynecologic cancer centers. Therefore, we might not have presented the clinical outcomes of the recurrent patients objectively and equally since the treatment of recurrences was not uniform, and changed according to the institutional practices at that time.

It has been reported that the clinical behavior of MOC is distinctly different from serous EOC and the prognosis of MOC is worse when compared to other histologies $[6-9,14,18-21]$. Hess et al. [18] have reported that MOC has a HR of 2.94 for progression and a HR of 3.08 for death in a study of 27 women with stage III/IV MOC. Winter et al. [19] reported that mucinous histology was associated with a worse PFS and OS compared with serous carcinomas in a study including 34 women with stage III MOC. In that study, the median PFS was 10.5 months whereas the median OS was 14.8 months for women with MOC.

In a meta-analysis consisting of 264 women with stage III/IV MOC, Mackay et al. [20] reported that patients with MOC had an increased risk of death (HR 2.66, 95\% CI 2.29-3.08) and disease-progression (HR 2.10, 95\% CI 1.842.41) compared to those with serous carcinoma. Patients with mucinous histology had an estimated median PFS of 7.6 months and a median OS of 14.6 months in that 


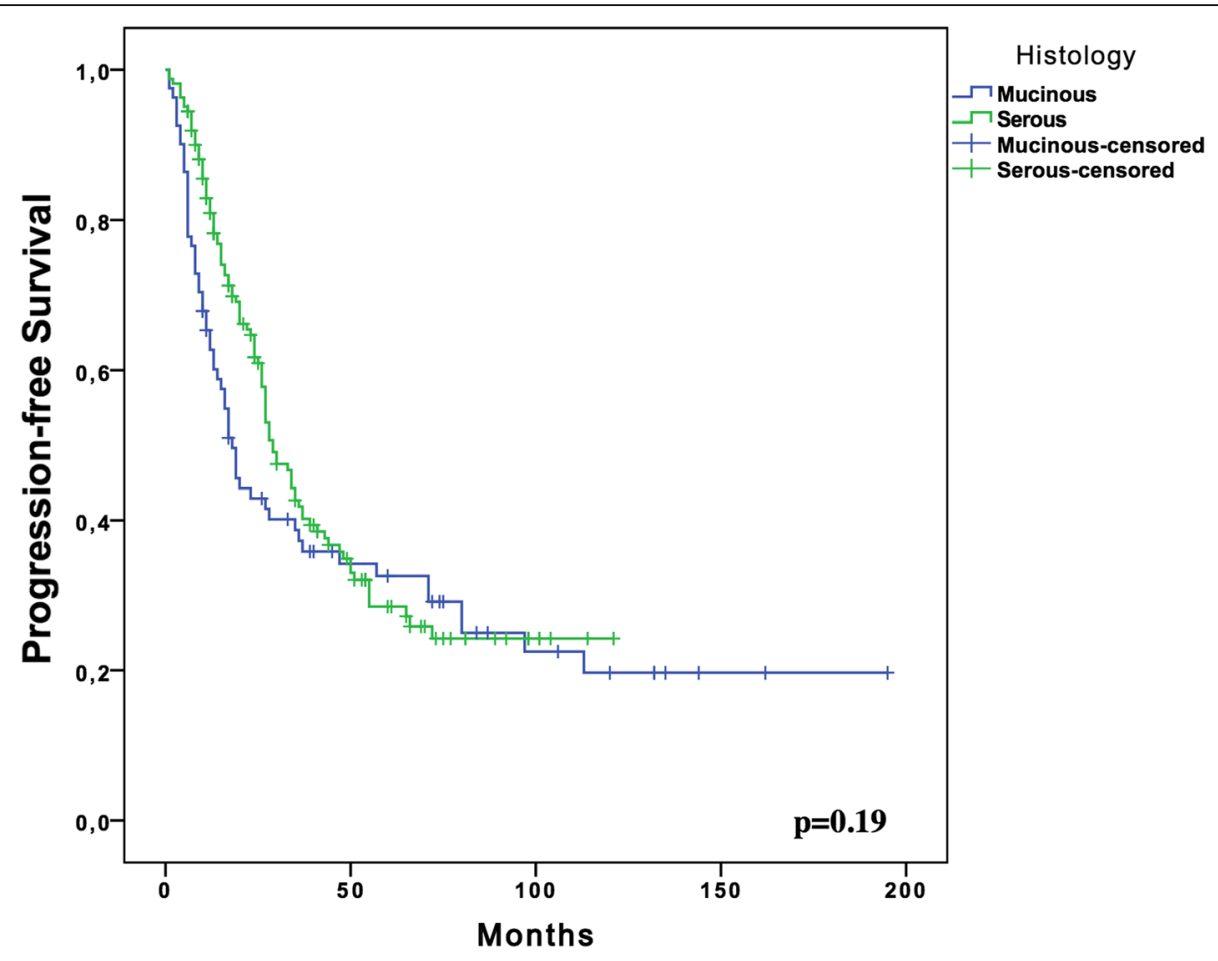

Fig. 1 Kaplan Meier Plots for progression free survival of the women with Stage III mucinous $(n=81)$ and serous $(n=162)$ ovarian cancer

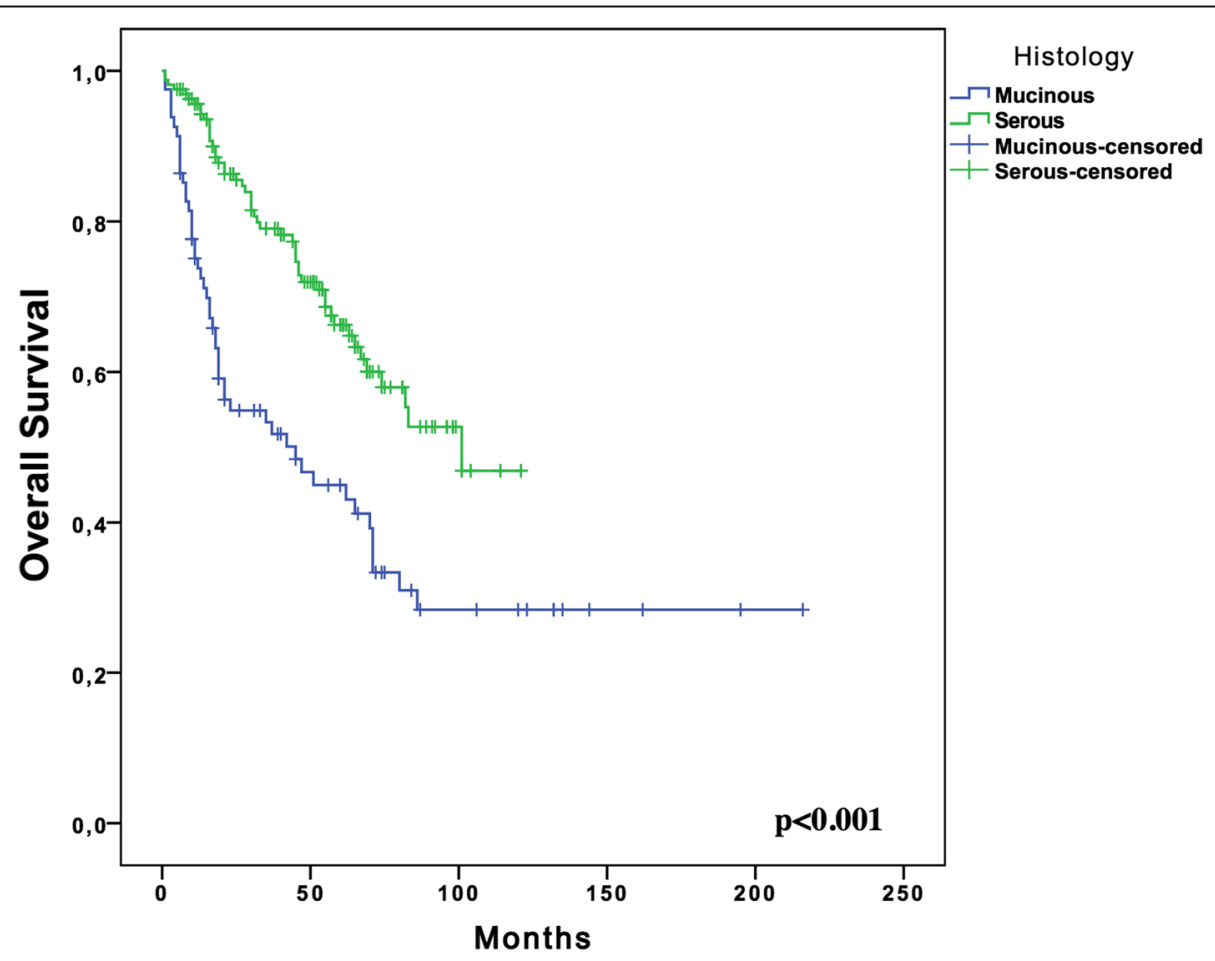

Fig. 2 Kaplan Meier Plots for overall survival of the women with Stage III mucinous $(n=81)$ and serous $(n=162)$ ovarian cancer 
Table 2 Univariate and multivariate analyses for overall survival in the entire cohort (stage III mucinous [ $n=81]$ and serous [ $n=162]$ ovarian carcinoma)

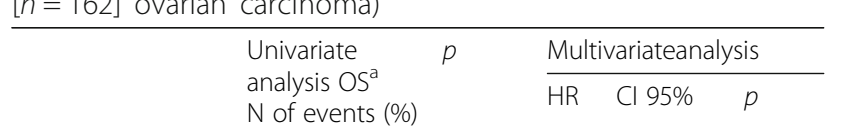

\begin{tabular}{ccc}
\hline Age, $y$ & & \\
$<52$ & $36 / 118(61.7 \%)$ & 0.163 \\
$\geq 52$ & $47 / 125(56.7 \%)$ & \\
Menopausal Status & & \\
Premenopausal & $33 / 96(56.6 \%)$ & 0.89 \\
Postmenopausal & $50 / 147(60.5 \%)$ & \\
Ca-125(IU/ml) & & \\
$<310$ & $46 / 121(56.2 \%)$ & 0.089 \\
$\geq 310$ & $37 / 122(62.2 \%)$ & \\
Grade & & \\
1 & $33 / 87(55.1 \%)$ & 0.74 \\
$2-3$ & $50 / 156(61.5 \%)$ & \\
Ascites & & \\
Present & $62 / 167(56.2 \%)$ & 0.371 \\
Absent & $21 / 76(66 \%)$ &
\end{tabular}

Retroperitoneal LN metastases

$\begin{array}{lll}\text { Present } & \text { 44/112 (39.2\%) } & 0.646 \\ \text { Absent } & 55 / 131(41.9 \%) & \\ \text { Peritoneal cytology } & & \\ \text { Positive } & 73 / 198(56.5 \%) & 0.215 \\ \text { Negative } & 10 / 45(71.8 \%) & \\ \text { Stage } & & \\ \text { IIIA1 } & 6 / 39(78.4 \%) & 0.001 \\ \text { IIIA2, IIIB, IIIC } & 77 / 204(55.6 \%) & \end{array}$

Appendiceal Involvement

$\begin{array}{ll}\text { Present } & 41 / 88(45 \%)\end{array} \quad<0.001$

Omental Involvement

$\begin{array}{ll}\text { Present } & 71 / 174(52 \%) \quad<0.001 \\ \text { Absent } & 12 / 69(77.6 \%)\end{array}$

Peritoneal Involvement

$\begin{array}{llllll}\text { Present } & 67 / 160(49.2 \%) & <0.001 & 2.39 & 1.38-4.14 & 0.002 \\ \text { Absent } & 16 / 83(76.9 \%) & & & & \end{array}$

Histologic Subtype

$\begin{array}{llllll}\text { Mucinous } & 41 / 81(44.9 \%) & <0.001 & 2.28 & 1.53-3.40 & <0.001 \\ \text { Serous } & 42 / 162(66.3 \%) & & & & \end{array}$

${ }^{a}: 5$-year overall survival rate

Abbreviations: OS Overall Survival, $L N$ Lymph node, $H R$ Hazard ratio, $C I$ Confidence interval, $y$ Year, $N$ number

meta-analysis. Bamias et al. [21] reported the median OS as 15.0 months for 21 women with stage III/IV MOC compared to 45.0 months for 389 women with stage III/IV
Table 3 Univariate and multivariate analyses for overall survival in women with stage III mucinous ovarian carcinoma $(n=81)$

\begin{tabular}{|c|c|c|c|c|c|}
\hline & \multirow{2}{*}{$\begin{array}{l}\text { Univariate } \\
\text { analysis OS } \\
\mathrm{N} \text { of events (\%) }\end{array}$} & \multirow[t]{2}{*}{$p$} & \multicolumn{3}{|c|}{ Multivariate analysis } \\
\hline & & & $\overline{H R}$ & Cl 95\% & $p$ \\
\hline \multicolumn{6}{|l|}{ Age, y } \\
\hline$<54$ & 17/39 (52.2\%) & 0.126 & & & \\
\hline$\geq 54$ & $24 / 42(38.1 \%)$ & & & & \\
\hline \multicolumn{6}{|l|}{ Menopausal Status } \\
\hline Premenopausal & 15/32 (49\%) & 0.49 & & & \\
\hline Postmenopausal & $26 / 49(42 \%)$ & & & & \\
\hline \multicolumn{6}{|l|}{ Ca-125(IU/ml) } \\
\hline$<126$ & 19/40 (49.2\%) & 0.42 & & & \\
\hline$\geq 126$ & $22 / 41(40.4 \%)$ & & & & \\
\hline \multicolumn{6}{|l|}{ Grade } \\
\hline 1 & 16/29 (36\%) & 0.98 & & & \\
\hline $2-3$ & $25 / 52(48 \%)$ & & & & \\
\hline \multicolumn{6}{|l|}{ Ascites } \\
\hline Present & $24 / 42(37.4 \%)$ & 0.174 & & & \\
\hline Absent & $17 / 39(52.4 \%)$ & & & & \\
\hline \multicolumn{6}{|l|}{ LN metastases } \\
\hline Present & 13/21 (27.9\%) & 0.433 & & & \\
\hline Absent & $28 / 60(50.4 \%)$ & & & & \\
\hline \multicolumn{6}{|l|}{ Peritoneal cytology } \\
\hline Positive & $35 / 61(36.8 \%)$ & 0.092 & & & \\
\hline Negative & $6 / 20(67.7 \%)$ & & & & \\
\hline \multicolumn{6}{|c|}{ Appendiceal Involvement } \\
\hline Present & 18/29 (30.9\%) & 0.180 & & & \\
\hline Absent & $23 / 52(51.9 \%)$ & & & & \\
\hline \multicolumn{6}{|c|}{ Omental Involvement } \\
\hline Present & $35 / 61(37 \%)$ & 0.008 & & & \\
\hline Absent & $6 / 20(68.4 \%)$ & & & & \\
\hline \multicolumn{6}{|l|}{ Stage } \\
\hline$\||| A 1$ & $2 / 13(83.9 \%)$ & 0.002 & & & \\
\hline$\|I\| A 2,\|I B\| \mid C$, & $39 / 68(37 \%)$ & & & & \\
\hline \multicolumn{6}{|l|}{ Debulking } \\
\hline Maximal & $6 / 27(74.3 \%)$ & $<0.001$ & 0.37 & $0.16-0.86$ & 0.021 \\
\hline Optimal & $35 / 54(30.1 \%)$ & & & & \\
\hline
\end{tabular}

a:5-year overall survival rate

Abbreviations: MOC Mucinous Ovarian Carcinoma, OS Overall Survival, LN Lymph node, HR Hazard ratio, Cl Confidence interval, y Years

ovarian high-grade serous carcinoma. In a case-control study, Karabuk et al. [14] have reported the median PFS and OS as 7.0 and 35.0 months, respectively, for 50 women with stage III/IV MOC. The authors concluded that the risk of death for MOC patients was significantly higher than that of serous EOC patients (HR 2.14, 95\% CI 1.34-3.42). In the current study, we have found out the median PFS 
and OS as 18.0 and 45.0 months, respectively, for women with stage III MOC who have undergone maximal or optimal CRS. The corresponding figures were 29.0 and 101.0 months, respectively, for the serous counterpart. There was no significant difference between the cases and the controls in terms of PFS. However, women with MOC were 2.3 times more likely to die of their tumors when compared to patients with serous EOC in the current study. Table 4 compares the findings of the current study with those of previous studies.

Using the Surveillance, Epidemiology and End Results (SEER) database, Schiavone et al. [7] reported that the HR for OS was 1.60 for women with stage III MOC. The 5 -year survival rate for women with stage III serous EOC was $33.6 \%$ compared with $25.7 \%$ for MOC. The corresponding rates were $66.3 \%$, and $44.9 \%$, respectively, in our study. It should be emphasized that the SEER database lacks several important variables such as extent and outcome of initial surgery including the size of RD, type of adjuvant chemotherapy, and recurrence. However, all patients (cases and controls) in the current study underwent maximal or optimal CRS followed by paclitaxel/carboplatin chemotherapy and cases were matched to controls in terms of age, tumor grade, substage of disease, and extent of RD.

Favorable prognostic factors such as younger patient age, lower tumor grade, and less peritoneal carcinomatosis have been reported for women with $\operatorname{MOC}[9,22]$. However, maximal cytoreduction was identified as the sole independent prognostic factor for increased PFS and OS in the current study. The volume of tumor left after primary CRS depends on the number and the size of the tumor elements [5]. We were not able to define the number of lesions left after initial surgery in this retrospective analysis. The maximal diameter of the largest residual tumor nodule is a very crude estimate of $\mathrm{RD}[5,23]$, but it still gave valuable prognostic information in our study.
Melamed et al. [13] have recently reported that cytoreduction to no gross RD is associated with a hazard reduction of $54 \%$ compared to any gross RD in MOCs.. The optimal chemotherapy regimen for MOC has not been clarified yet; so aggressive CRS seems to be the only effective treatment to improve the prognosis in advanced-stage MOC [12]. Our finding associated with maximal cytoreduction as the sole independent prognostic factor for both PFS and OS in women with stage III MOC is in agreement with previous reports $[12,13]$.

The most important limitation of the current study is the fact that central pathology review was not performed. There is now increasing recognition that many MOCs may in fact be metastatic mucinous neoplasms from other primary sites [7]. Differentiating MOC from gastrointestinal cancer [24, 25], mainly carcinomas of appendix, and colorectal cancer by morphology alone can be difficult. It should be reminded that no patients receiving neoadjuvant chemotherapy were included in the current study and all patients have undergone surgical exploration which commonly would have identified a cancer of gastrointestinal origin. Additionally, immunohistohemical studies were performed in cases where metastatic tumors could not be excluded. Recent data suggests that the application of updated criteria results in reliable histopathological diagnoses based on the cell type [26]. Nevertheless, our study was restricted by the lack of a central pathology review as many previous reports $[7,13,20,27]$.

The major strength of the current study is the inclusion of a relatively large number of patients with stage III MOC. Our study has the advantage that all included patients were treated with the standard paclitaxel/carboplatin regimen. The standard surgery and the standard postoperative adjuvant chemotherapy regimen seem to improve the reliability of our findings and decrease the probable effects of the confounders.

Table 4 Comparison of the findings of the current study with those of previous studies associated with advanced mucinous ovarian carcinoma

\begin{tabular}{llllll}
\hline Author & Number of women with MOC & Stage of disease & Extent of residual disease & Median PFS (months) & Media OS (months) \\
\hline Hess, 2004 [18] & 27 & III, IV & optimal or suboptimal & 5.7 & 12.0 \\
Pectasides, 2005 [27] & 47 & III, IV & optimal or suboptimal & 11.8 & 33.2 \\
Winter, 2007 [19] & 34 & III & optimal or suboptimal & 10.5 & 14.8 \\
Bamias, 2010 [8] & 24 & III, IV & optimal or suboptimal & NR & 15.4 \\
Mackay, 2010 [20] & 264 & III, IV & optimal or suboptimal & 7.6 & 14.6 \\
Bamias, 2012 [21] & 21 & III, IV & optimal or suboptimal & NR & 15.0 \\
Karabuk, 2013 [14] & 50 & III, IV & optimal or suboptimal & 7.0 & 35.0 \\
Current study & 81 & III & maximal or optimal & 18.0 & 45.0 \\
\hline
\end{tabular}


We conclude that women with stage III MOC seem to be 2.3 times more likely to die of their tumors when compared to patients with serous EOC. Maximal cytoreduction seems to be the sole independent prognostic factor for increased OS in women with stage III MOC. As the extent of RD is a modifiable prognostic factor, it seems reasonable to perform maximal CRS whenever possible in order to improve the outcomes of those women.

\section{Acknowledgments}

Authors declare that there is neither financial nor academic support or relationships that may pose potential conflict of interest. No funding was required for the study and the preparation of the text. No assistance by individuals other than the authors was required for writing or other purposes.

\section{Funding}

There has been no funding for conducting the study and writing the manuscript.

\section{Availability of data and materials}

The datasets used and/or analyses during the current study are available from the corresponding author on reasonable request.

\section{Authors' contributions}

ZFC: Conceptualization, Data curation, Investigation, Methodology, Software, Validation, writing - original draft, writing - review \& editing. EK:

Conceptualization, Data curation, Investigation, Validation: Writing - original draft. MO: Data curation, Formal analysis, Investigation, Methodology, Software, writing - original draft: Writing - review \& editing. ATT: Conceptualization, Formal analysis, Methodology, Supervision, Validation. Writing - review \& editing. MMM: Conceptualization, Data curation, Formal analysis, Investigation, Methodology, Software, Supervision, Validation, writing - original draft, writing - review \& editing. ST: Conceptualization, Formal analysis, Methodology, Software, Supervision, Validation, writing - review \& editing. MES: Conceptualization, Methodology, Supervision, Validation, Visualization, writing - review \& editing. HS: Data curation, Formal analysis, Investigation, Software. SCU: Data curation, Formal analysis, Methodology, Supervision, Visualization. OA: Data curation, Formal analysis, Methodology, Supervision, Visualization. KG: Data curation, Formal analysis, Investigation, Validation. TG: Conceptualization, Investigation, Methodology, Supervision, Validation, writing - review \& editing. MFK: Conceptualization, Investigation, Methodology, Supervision, Validation, writing - review \& editing. AA: Conceptualization, Formal analysis, Methodology, Supervision, Visualization, writing - review \& editing. All authors read and approved the final manuscript.

\section{Ethics approval and consent to participate}

Written and signed informed consents were obtained from all participants in the study.

Institutional Review Board approval (IRB Approval Number: 05, Date: November 7th 2017)

\section{Consent for publication}

The manuscript does not contain any individual's data requiring consent for publication.

\section{Competing interests}

The authors declare that they have no competing interests.

\section{Publisher's Note}

Springer Nature remains neutral with regard to jurisdictional claims in published maps and institutional affiliations.

\section{Author details}

'Department of Gynecologic Oncology, Zekai Tahir Burak Women's Health Training and Research Hospital, Faculty of Medicine, University of Health Sciences, Ankara, Turkey. ${ }^{2}$ Faculty of Health Sciences, Department of Obstetrics and Gynecology, Acibadem University, Istanbul, Turkey. ${ }^{3}$ Department of Gynecologic Oncology, Etlik Zubeyde Hanim Women's
Health Training and Research Hospital, Faculty of Medicine, University of Health Sciences, Ankara, Turkey. ${ }^{4}$ Division of Gynecologic Oncology, Department of Obstetrics and Gynecology, School of Medicine, AnkaraUniversity, Ankara, Turkey. ${ }^{5}$ Department of General Surgery, Kanuni Sultan Suleyman Teaching and Research Hospital, Faculty of Medicine, University of Health Sciences, Istanbul, Turkey. ${ }^{6}$ Department of Gynecologic Oncology, Kanuni Sultan Suleyman Teaching and Research Hospital, Faculty of Medicine, University of Health Sciences, Istanbul, Turkey. ${ }^{7}$ Department of Gynecologic Oncology, Tepecik Education and Research Hospital, Faculty of Medicine, University of Health Sciences, Izmir, Turkey. ${ }^{8}$ Division of Gynecologic Oncology, Department of Obstetrics and Gynecology, Faculty of Medicine, BaskentUniversity, Ankara, Turkey.

Received: 27 April 2018 Accepted: 22 October 2018

Published online: 30 October 2018

\section{References}

1. Earp MA, Kelemen LE, Magliocco AM, Swenerton KD, Chenevix-Trench G, Australian Cancer S, Australian Ovarian Cancer Study G, Lu Y, Hein A, Ekici $A B$, Beckmann MW, Fasching PA, Lambrechts D, Despierre E, Vergote I, Lambrechts S, Doherty JA, Rossing MA, Chang-Claude J, Rudolph A, Friel G, Moysich KB, Odunsi K, Sucheston-Campbell L, Lurie G, Goodman MT, Carney ME, Thompson PJ, Runnebaum IB, Durst M, Hillemanns P, Dork T, Antonenkova N, Bogdanova N, Leminen A, Nevanlinna H, Pelttari LM, Butzow R, Bunker CH, Modugno F, Edwards RP, Ness RB, du Bois A, Heitz F, Schwaab I, Harter P, Karlan BY, Walsh C, Lester J, Jensen A, Kjaer SK, Hogdall CK, Hogdall E, Lundvall L, Sellers TA, Fridley BL, Goode EL, Cunningham JM, Vierkant RA, Giles GG, Baglietto L, Severi G, Southey MC, Liang D, Wu X, Lu K, Hildebrandt MA, Levine DA, Bisogna M, Schildkraut JM, Iversen ES, Weber RP, Berchuck A, Cramer DW, Terry KL, Poole EM, Tworoger SS, Bandera EV, Chandran U, Orlow I, Olson SH, Wik E, Salvesen HB, Bjorge L, Halle MK, van Altena AM, Aben KK, Kiemeney LA, Massuger LF, Pejovic T, Bean YT, Cybulski C, Gronwald J, Lubinski J, Wentzensen N, Brinton LA, Lissowska J, GarciaClosas M, Dicks E, Dennis J, Easton DF, Song H, Tyrer JP, Pharoah PD, Eccles D, Campbell IG, Whittemore AS, McGuire V, Sieh W, Rothstein JH, Flanagan JM, Paul J, Brown R, Phelan CM, Risch HA, McLaughlin JR, Narod SA, Ziogas A, Anton-Culver H, Gentry-Maharaj A, Menon U, Gayther SA, Ramus SJ, Wu AH, Pearce CL, Pike MC, Dansonka-Mieszkowska A, Rzepecka IK, Szafron LM, Kupryjanczyk J, Cook LS, Le ND, Brooks-Wilson A, Ovarian Cancer Association C (2014) Genome-wide association study of subtype-specific epithelial ovarian cancer risk alleles using pooled DNA. Hum Genet 133 (5): 481-497. doi:https://doi.org/10.1007/s00439-013-1383-3.

2. Prat J. Ovarian carcinomas: five distinct diseases with different origins, genetic alterations, and clinicopathological features. Virchows Arch. 2012;460(3):237-49. https://doi.org/10.1007/s00428-012-1203-5.

3. McGuire $V$, Jesser CA, Whittemore AS. Survival among U.S. women with invasive epithelial ovarian cancer. Gynecol Oncol. 2002;84(3):399-403. https://doi.org/10.1006/gyno.2001.6536.

4. Omura GA, Brady MF, Homesley HD, Yordan E, Major FJ, Buchsbaum HJ, Park RC. Long-term follow-up and prognostic factor analysis in advanced ovarian carcinoma: the gynecologic oncology group experience. J Clin Oncol. 1991;9(7):1138-50. https://doi.org/10.1200/JCO.1991.9.7.1138.

5. Makar AP, Baekelandt M, Trope CG, Kristensen GB. The prognostic significance of residual disease, FIGO substage, tumor histology, and grade in patients with FIGO stage III ovarian cancer. Gynecol Oncol. 1995:56(2): $175-80$

6. Zaino RJ, Brady MF, Lele SM, Michael H, Greer B, Bookman MA. Advanced stage mucinous adenocarcinoma of the ovary is both rare and highly lethal: a gynecologic oncology group study. Cancer. 2011;117(3):554-62. https://doi.org/10.1002/cncr.25460.

7. Schiavone MB, Herzog TJ, Lewin SN, Deutsch I, Sun X, Burke WM, Wright JD. Natural history and outcome of mucinous carcinoma of the ovary. Am J Obstet Gynecol. 2011;205(5):480 e481-8. https://doi.org/10.1016/j.ajog.2011.06.049.

8. Bamias A, Psaltopoulou T, Sotiropoulou M, Haidopoulos D, Lianos E, Bournakis E, Papadimitriou C, Rodolakis A, Vlahos G, Dimopoulos MA. Mucinous but not clear cell histology is associated with inferior survival in patients with advanced stage ovarian carcinoma treated with platinumpaclitaxel chemotherapy. Cancer. 2010;116(6):1462-8. https://doi.org/10. 1002/cncr.24915.

9. Alexandre J, Ray-Coquard I, Selle F, Floquet A, Cottu P, Weber B, Falandry C Lebrun D, Pujade-Lauraine E, Gineco (2010) Mucinous advanced epithelial 
ovarian carcinoma: clinical presentation and sensitivity to platinumpaclitaxel-based chemotherapy, the GINECO experience. Ann Oncol 21 (12): 2377-2381. doi:https://doi.org/10.1093/annonc/mdq257.

10. Massad LS, Gao F, Hagemann I, Powell M. Clinical outcomes among women with mucinous adenocarcinoma of the ovary. Gynecol Obstet Investig. 2016; 81(5):411-5. https://doi.org/10.1159/000441791.

11. Nakayama K, Takebayashi Y, Nakayama S, Hata K, Fujiwaki R, Fukumoto M, Miyazaki K. Prognostic value of overexpression of p53 in human ovarian carcinoma patients receiving cisplatin. Cancer Lett. 2003;192(2):227-35.

12. Shimada M, Kigawa J, Ohishi Y, Yasuda M, Suzuki M, Hiura M, Nishimura R, Tabata T, Sugiyama T, Kaku T. Clinicopathological characteristics of mucinous adenocarcinoma of the ovary. Gynecol Oncol. 2009;113(3):331-4. https://doi.org/10.1016/j.ygyno.2009.02.010.

13. Melamed A, Manning-Geist B, Bregar AJ, Diver EJ, Goodman A, Del Carmen MG, Schorge JO, Rauh-Hain JA. Associations between residual disease and survival in epithelial ovarian cancer by histologic type. Gynecol Oncol. 2017; 147(2):250-6. https://doi.org/10.1016/j.ygyno.2017.08.003.

14. Karabuk E, Kose MF, Hizli D, Taskin S, Karadag B, Turan T, Boran N, Ozfuttu A, Ortac UF. Comparison of advanced stage mucinous epithelial ovarian cancer and serous epithelial ovarian cancer with regard to chemosensitivity and survival outcome: a matched case-control study. J Gynecol Oncol. 2013;24(2):160-6. https://doi.org/10.3802/jgo.2013.24.2.160.

15. Prat J, Oncology FCG. Staging classification for cancer of the ovary, fallopian tube, and peritoneum. Int J Gynaecol Obstet. 2014;124(1):1-5. https://doi.org/10.1016/j.jijgo.2013.10.001.

16. Kurman RJ, Carcangiu, M.L., Herrington, C.S., Young, R.H. (2014) WHO classification of Tumours of female reproductive organs. Fourth edition. Lyon. IARC chapter 1: tumors of the ovary.

17. FAaD T, Devilee P. World health organization Classfication of tumors. Pathology \& Genetics of Tumours of the breast and female genital organs. Lyon: IARC (International Agency for Research on Cancer) press; 2003. p. 153-8.

18. Hess V, A'Hern R, Nasiri N, King DM, Blake PR, Barton DP, Shepherd JH, Ind T, Bridges J, Harrington K, Kaye SB, Gore ME. Mucinous epithelial ovarian cancer: a separate entity requiring specific treatment. J Clin Oncol. 2004 22(6):1040-4. https://doi.org/10.1200/JCO.2004.08.078.

19. Winter WE 3rd, Maxwell GL, Tian C, Carlson JW, Ozols RF, Rose PG, Markman M, Armstrong DK, Muggia F, WP MG, Gynecologic Oncology Group S. Prognostic factors for stage III epithelial ovarian cancer: a gynecologic oncology group study. J Clin Oncol. 2007;25(24):3621-7. https://doi.org/10. 1200/JCO.2006.10.2517

20. Mackay HJ, Brady MF, Oza AM, Reuss A, Pujade-Lauraine E, Swart AM, Siddiqui N, Colombo N, Bookman MA, Pfisterer J, du Bois A, Gynecologic Cancer I. Prognostic relevance of uncommon ovarian histology in women with stage III/IV epithelial ovarian cancer. Int J Gynecol Cancer. 2010;20(6): 945-52. https://doi.org/10.1111/IGC.0b013e3181dd0110.

21. Bamias A, Sotiropoulou M, Zagouri F, Trachana P, Sakellariou K, Kostouros E, Kakoyianni K, Rodolakis A, Vlahos G, Haidopoulos D, Thomakos N, Antsaklis A, Dimopoulos MA. Prognostic evaluation of tumour type and other histopathological characteristics in advanced epithelial ovarian cancer, treated with surgery and paclitaxel/carboplatin chemotherapy: cell type is the most useful prognostic factor. Eur J Cancer. 2012;48(10):1476-83. https://doi.org/10.1016/j.ejca.2011.09.023.

22. Pignata S, Ferrandina G, Scarfone G, Scollo P, Odicino F, Cormio G, Katsaros D, Villa A, Mereu L, Ghezzi F, Manzione L, Lauria R, Breda E, Alletti DG, Ballardini M, Lombardi AV, Sorio R, Mangili G, Priolo D, Magni G, Morabito A. Activity of chemotherapy in mucinous ovarian cancer with a recurrence free interval of more than 6 months: results from the SOCRATES retrospective study. BMC Cancer. 2008;8:252. https://doi.org/10.1186/1471-2407-8-252.

23. Hoskins WJ, McGuire WP, Brady MF, Homesley HD, Creasman WT, Berman $M$, Ball H, Berek JS. The effect of diameter of largest residual disease on survival after primary cytoreductive surgery in patients with suboptimal residual epithelial ovarian carcinoma. Am J Obstet Gynecol. 1994;170(4):974-9 discussion 979-980.

24. McBroom JW, Parker MF, Krivak TC, Rose GS, Crothers B. Primary appendiceal malignancy mimicking advanced stage ovarian carcinoma: a case series. Gynecol Oncol. 2000;78(3 Pt 1):388-90. https://doi.org/10.1006/gyno.2000.5913.

25. Sehouli J, Kopetsch OJ, Ricke J, Buchmann E, Stengel D, Riess H, Weidemann H, Schaper F, Freiesleben W, Lichtenegger W. Primary mucinous adenocarcinoma of the appendix: a rare entity in the differential diagnosis of ovarian cancer. J Obstet Gynaecol Res. 2000;26(5):333-9.
26. Gilks CB, lonescu DN, Kalloger SE, Kobel M, Irving J, Clarke B, Santos J, Le N, Moravan V, Swenerton K, Cheryl Brown Ovarian Cancer Outcomes Unit of the British Columbia Cancer A. Tumor cell type can be reproducibly diagnosed and is of independent prognostic significance in patients with maximally debulked ovarian carcinoma. Hum Pathol. 2008;39(8):1239-51. https://doi.org/10.1016/j.humpath.2008.01.003.

27. Pectasides D, Fountzilas G, Aravantinos G, Kalofonos HP, Efstathiou E, Salamalekis E, Farmakis D, Skarlos D, Briasoulis E, Economopoulos T, Dimopoulos MA. Advanced stage mucinous epithelial ovarian cancer: the Hellenic cooperative oncology group experience. Gynecol Oncol. 2005;97(2): 436-41. https://doi.org/10.1016/j.ygyno.2004.12.056.
Ready to submit your research? Choose BMC and benefit from:

- fast, convenient online submission

- thorough peer review by experienced researchers in your field

- rapid publication on acceptance

- support for research data, including large and complex data types

- gold Open Access which fosters wider collaboration and increased citations

- maximum visibility for your research: over $100 \mathrm{M}$ website views per year

At $\mathrm{BMC}$, research is always in progress.

Learn more biomedcentral.com/submissions 